\title{
ALTERAÇÕES DOS ATRIBUTOS FÍSICOS DE UM LATOSSOLO VERMELHO SUBMETIDO A DIFERENTES SISTEMAS DE MANEJO ${ }^{1}$
}

\author{
Physical attribute alterations of an Oxisol under different tillage systems ${ }^{1}$
}

\author{
Jose Luiz Rodrigues Torres ${ }^{2}$, Adelar Jose Fabian ${ }^{3}$, Marcos Gervasio Pereira ${ }^{4}$
}

\begin{abstract}
RESUMO
O cultivo do solo pode alterar alguns atributos físicos em relação ao solo não cultivado. Diante disso, neste estudo objetivouse verificar as alterações provocadas pelos sistemas de uso do solo sobre alguns atributos físicos de um Latossolo Vermelho no Triângulo Mineiro. Os tratamentos utilizados foram: Campo nativo (CN) (testemunha); preparo convencional do solo (PC); pastagem irrigada de braquiária sob pastejo rotacionado tipo VoIsin (PT) e Semeadura direta (SD). Utilizou-se o delineamento inteiramente casualizado, com 4 repetições, onde foram avaliados os seguintes atributos físicos: densidade do solo (Ds), volume total de poros (VTP), microporosidade (MI), macroporosidade (MA), condutividade hidráulica saturada $(\mathrm{K} \theta)$, resistência mecânica do solo à penetração (RP) e o índice de sensibilidade (Is). Nas áreas sob PC, SD e PT não foram observadas alterações significativas com relação aos atributos físicos avaliados. Para as profundidades avaliadas só ocorreram diferenças significativas entre as profundidades de 0,0 - 0,05 e a de 0,15 a 0,20 m para os parâmetros Ds e VTP. PC, SD, PT e CN apresentaram valores médios de volumes de MA próximos ou superiores daquele considerado ideal $\left(0,33 \mathrm{dm}^{-3} \mathrm{dm}^{-3}\right)$. Apenas no $\mathrm{CN}$ não ocorreu valores maiores que $2 \mathrm{MPa}$. No CN, PC, e SD não ocorreram limitações ao desenvolvimento das culturas até a profundidade de $0,08 \mathrm{~m}$. O Is calculado para os atributos CC e $\mathrm{K} \theta$ nos sistemas PC e PT demonstraram o efeito prejudicial desses sistemas de manejo sobre a estrutura do solo, quando comparados ao SD.
\end{abstract}

Termos para indexação: Cerrado, densidade do solo, resistência do solo à penetração, condutividade hidráulica, macroporosidade, microporosidade.

\begin{abstract}
The cultivation of the soil may alter some physical attributes compared to non cultivated soil. The objective of this study to verify changes caused by land use systems on some physical attributes of an Oxisol in the Triângulo Mineiro. The used treatments were: Native field (CN) (control); Conventional preparation of the soil (PC); Irrigated pasture of brachiaria under pasture alternate (PT) and Direct tillage (DT). A completely randomized design with four replicates were evaluated in the following physical attributes: density of the soil (Ds), total volume of pores (VTP), microporosity (MI), macroporosity (MA), saturated hydraulic conductivity $(\mathrm{K} \theta)$, mechanical resistance of the soil to the penetration (RP) and the index sensibility (Is). Areas under PC, SD and PT significant changes were not observed with respect to the physical attributes assessed. For the depths evaluated, significant differences were observed only between the depths from 0.00 to 0.05 and from 0.15 to $0.20 \mathrm{~m}$ for the parameters Ds and VTP. PC, $\mathrm{SD}, \mathrm{PT}$ and $\mathrm{CN}$ presented average volumes of MA near or above that considered ideal $\left(0.33 \mathrm{dm}^{-3} \mathrm{dm}^{-3}\right)$. Only on $\mathrm{CN}$, values higher than $2 \mathrm{MPa}$ were not observed. On CN values greater than $2 \mathrm{MPa}$; In CN, PC and SD there were no limitations at crop development to a depth of $0.08 \mathrm{~m}$. The calculated Is attributes $\mathrm{K} \theta$ and $\mathrm{CC}$ in the systems PC and PT demonstrated the harmful effect of these management systems on soil structure, when compared to SD.
\end{abstract}

Index terms: Cerrado, soil density, soil resistance to penetration, hydraulic conductivity, macroporosity, microporosity.

(Recebido em 1 de abril de 2009 e aprovado em 8 de outubro de 2010)

\section{INTRODUÇÃO}

O Cerrado é o segundo maior bioma brasileiro em extensão geográfica, apresenta alta diversidade em espécies vegetais, sazonalidade acentuada e está submetido a um forte processo de antropização devido à expansão da fronteira agrícola (Pereira et al., 2010). A utilização e a ocupação agrícola neste bioma nas últimas décadas têm ocorrido com grande intensidade, por meio do desmatamento generalizado, uso da mecanização intensiva e de grandes quantidades de insumos químicos.

A exploração inadequada do solo nesta região favorece a degradação, principalmente pela intensificação dos processos de erosão e compactação, pois alteram as propriedades físicas, químicas e biológicas do solo, causando baixos rendimentos das culturas cultivadas e problemas com relação à conservação do solo (Leite et al., 2010). No entanto, estes solos quando submetidos a

${ }^{1}$ Estudo conduzido na área experimental do Instituto Federal do Triângulo Mineiro (IFTM) campus Uberaba

${ }^{2}$ Instituto Federal do triangulo Mineiro/IFTM - Campus Uberaba - Avenida Edílson L. Mendes - 300 - 38045-000 - Uberaba, MG - jlrtorres@terra.com.br ${ }^{3}$ Instituto Federal do triangulo Mineiro/IFTM - Uberaba, MG

${ }^{4}$ Universidade Federal Rural do Rio de Janeiro/UFRRJ - Departamento de Solos - Seropédica, RJ 
determinados sistemas de manejo, tendem a um novo estado de equilíbrio, refletido em diferentes manifestações de seus atributos físicos (Silva et al., 2005).

O cultivo do solo pode alterar alguns atributos físicos em relação ao solo não cultivado, como a densidade do solo, porosidade total e na distribuição de poros por tamanho (Bertol et al., 2004). Normalmente, o aumento do volume de poros e da permeabilidade que ocorre na camada preparada convencionalmente, facilita o armazenamento de ar e crescimento das raízes (Bertol et al., 2000), entretanto, abaixo desta camada, essas propriedades podem apresentar comportamento inverso ao da superfície (Costa et al., 2003), especialmente quando essas áreas são comparadas as de semeadura direta e campo nativo.

No sistema de semeadura direta, ocorre menor revolvimento do solo e a manutenção total ou parcial de resíduos vegetais na superfície, os quais são responsáveis pela manutenção e melhoria dos atributos físicos do solo (Castro Filho et al., 1998). Nesse sistema tem sido observada a redução do volume de macroporos, elevação da densidade do solo (Bertol et al., 2001) e aumento da estabilidade dos agregados na superfície (Carpenedo \& Mielniczuck, 1990), favorece a infiltração de água e dificulta o escoamento superficial, com isso causa a diminuição dos processos erosivos que é considerado a principal causa da degradação dos solos agrícolas nesta áreas e no mundo (Costa et al., 2008). Entretanto, o tráfego de máquinas pesadas pode causar compactação superficial do solo, reduzindo a produtividade das culturas (Beutler \& Centurion, 2004).

Comparando áreas em semeadura direta com 4, 8 e 12 anos de implantação e área em plantio convencional (com 12 anos), Marcolan \& Anghinoni (2006) observaram que após 4 anos sob semeadura direta, o solo havia recuperado sua condição original para os atributos: densidade do solo, macro e microporosidade, porosidade total, estabilidade dos agregados e teor de carbono nas camadas superficiais $(0,0$ - 2,5; 2,5 - 7,5 e 7,5 - 15,0 cm). Em estudo semelhante, Silva et al. (2006) observaram aumento da macroporosidade no preparo convencional, quando comparado ao preparo reduzido e semeadura direta na camada de 7,5 - 12,5 cm e maior microporosidade na camada de $0-2,5 \mathrm{~cm}$ na semeadura direta quando comparado aos demais sistemas.

O tamanho, estado de agregação e a estabilidade dos agregados do solo podem ser determinados através de índices como o diâmetro médio ponderado (DMP), diâmetro médio geométrico (DMG) (Silva et al., 2005; Loss et al., 2009; Bilibio et al., 2010) e índice de estabilidade dos agregados (IEA) (Fontana et al., 2010). Além destes índices, também pode ser utilizado o índice de sensibilidade (Is) para avaliar a influência de diferentes tipos de cobertura vegetal e formas de manejo na estabilidade dos agregados, pois quanto maior o valor do Is mais próximo o solo estará de sua condição natural (Bolinder et al., 1999; Bertol et al., 2004).

Fontana et al. (2010), compararam dois solos (Latossolo e Argissolo amarelos) cultivados com 2 coberturas vegetais (Cana de açúcar e pastagem) e observaram que os valores de Is dos dois solos sob pasto foram maiores que os solos sob cana. Estes resultados indicam que as áreas de Argissolo amarelo, quando cultivadas com pastagem, estão mais próximas das condições naturais, sendo este comportamento decorrente da melhor agregação do solo. Os menores Is encontrados na área de cana refletem o efeito prejudicial do sistema de preparo convencional sobre a estrutura do solo. Diante deste contexto, o presente estudo teve como objetivo avaliar as alterações provocadas pelos sistemas de uso do solo sobre alguns atributos físicos de um Latossolo Vermelho em Uberaba-MG.

\section{MATERIAL E MÉTODOS}

O estudo foi conduzido na área experimental da Unidade I do Instituto Federal do Triângulo Mineiro campus Uberaba, localizado no município de Uberaba, localizado entre a latitude de $19^{\circ} 39^{\prime} 19^{\prime}$ ' S e a longitude de 47 $57^{\prime} 27^{\prime}$ ' W. O clima da região é classificado como Aw, tropical quente, segundo Köppen, com verão quente e chuvoso, inverno frio e seco. Ocorre um período chuvoso de outubro a abril, tendo uma estação seca de maio a setembro e outra chuvosa de dezembro e janeiro, tendo temperatura média anual de $23,2^{\circ} \mathrm{C}$, com máxima de $30,2^{\circ} \mathrm{C}$ e mínima de $17,6^{\circ} \mathrm{C}$ (Valle Junior et al., 2010). Silva et al. (2003) avaliaram os dados climatológicos na região abrangendo o período de 1914 a 2000 e destacaram que a precipitação média anual na região de Uberaba é de 1584,2 $\mathrm{mm}$ ano $^{-1}$, sendo que nos meses de dezembro/janeiro/ fevereiro os valores de precipitação variam entre 42,8 e $541 \mathrm{~mm}$ mês $^{-1}$, para uma série histórica de 62 anos.

O município de Uberaba faz parte da grande unidade de relevo do planalto arenítico-basáltico da Bacia do Paraná. A topografia é caracterizadas por superfícies planas ou ligeiramente onduladas, geologicamente formadas por rochas sedimentares em grande parte arenito, do período cretáceo da formação Bauru (Cruz et al., 2003). Segundo a Empresa Brasileira de Pesquisa Agropecuária - Embrapa (1982), os solos predominantes na região do Triângulo Mineiro são os Latossolos e os Argissolos com diferentes graus de fertilidade. 
O solo da área em estudo é um Latossolo Vermelho (Embrapa, 2006), textura franco-argilo-arenosa, com $220 \mathrm{~g} \mathrm{~kg}^{-1}$ de argila, $50 \mathrm{~g} \mathrm{~kg}^{-1}$ de silte e $730 \mathrm{~g} \mathrm{~kg}^{-1}$ de areia. O relevo foi caracterizado como suave ondulado.

Num delineamento experimental de blocos inteiramente casualizados, com 4 repetições, os sistemas de uso (tratamentos) selecionados para avaliação, consistiram em: 1 - Preparo convencional (PC) há mais de 20 anos (duas gradagens aradoras e duas niveladoras); 2 Semeadura direta (SD) há 4 anos; 3 - Pastagem (PT) de braquiária irrigada em pastoreio rotacionado, há 4 anos; 4 Campo Nativo (CN) (testemunha).

As amostragens para a avaliação dos atributos físicos foram realizadas em setembro de 2003. Em cada área foram selecionados, aleatoriamente, 4 pontos de amostragem com 3 subamostras em cada ponto. Foi feita uma trincheira onde se coletaram amostras com estrutura indeformada, utilizando-se amostrador de Uhland, com cilindros de aço inox com $5 \mathrm{~cm}$ de diâmetro e $5,2 \mathrm{~cm}$ de altura, nas profundidades de $0-5 ; 5-10 ; 10-15 ; 15-20 ; 20-30$ e 30-40 cm, totalizando 96 amostras.

A densidade do solo e os volumes de macroporos, microporos e total de poros foram determinados pelo método do anel volumétrico, conforme Blake \& Hartge (1986). Com o auxílio da mesa de tensão quantificou-se o volume de macroporos, determinando-se a quantidade de água retirada na amostra saturada após essa ter sido submetida à sucção de $60 \mathrm{~cm}$ de coluna de água durante 24 horas. As amostras foram secas a $105^{\circ} \mathrm{C}$ e pesadas para calcular a porosidade.

$\mathrm{O}$ volume total de poros foi calculado relacionandose a densidade do solo e a densidade de partículas, enquanto o volume de macroporos (MA) foi calculado pela diferença entre o volume total de poros (VTP) e o volume de microporos (MI), conforme destacado por Bertol et al. (2004).

A condutividade hidráulica saturada foi determinada em amostras indeformadas e saturadas usando um permeâmetro de carga constante (Klute \& Dirkensen, 1986).

A resistência do solo à penetração foi determinada utilizando-se o penetrômetro de Impacto Modelo IAA/ Planalsucar-Stolf), com ângulo de ponteira cônica de $30^{\circ}$, a partir da superfície do solo até a profundidade de $0,40 \mathrm{~m}$, em 10 pontos por parcela (Stolf, 1991).

A intensidade das alterações dos atributos físicos do solo em função dos diferentes usos foi estimada através do índice de sensibilidade (Is) sugerido por Bolinder et al. (1999), utilizando a equação 1:

$\mathrm{Is}=\mathrm{a}_{\mathrm{S}} / \mathrm{a}_{\mathrm{c}}$

Onde: Is = índice de sensibilidade; $\mathrm{a}_{\mathrm{s}}=$ valor do atributo em cada sistema de manejo (PC, PT e SD), e $a_{c}=$ valor do atributo do solo no $\mathrm{CN}$.
Quando o valor do índice (Is) se aproxima da unidade (um), significa pouca alteração provocada pelo sistema de manejo avaliado.

O Is é um índice que determina a semelhança existente entre duas ou mais áreas e pode ser utilizado para determinar o grau de alteração entre os atributos das áreas estudadas, por Isso mesmo pode ser aplicado sobre outras variáveis. Neste estudo os valores referentes aos tratamentos ao PC, PT e SD foram comparados ao $\mathrm{CN}$.

\section{RESULTADOS E DISCUSSÃO}

Não foram verificadas diferenças significativas entre os valores médios de densidade do solo (Ds) nas áreas sob plantio convencional (PC), pastagem (PT) e semeadura direta (SD), em todas as profundidades avaliadas. Entretanto, estes diferiram estatisticamente quando comparados ao campo nativo $(\mathrm{CN})$ (Tabela 1). Apesar dos valores médios terem sido superiores ao observado no CN $(1,38)$, estes ainda encontram-se abaixo do valor 1,60 $\mathrm{kg} \mathrm{dm}^{-3}$ estabelecido por Silva \& Rosolem (2001), como crítico para o desenvolvimento das culturas.

Para as profundidades estudadas, verifica-se que só ocorreram diferenças significativas entre as profundidades de $0,0-0,05$ e a de 0,15 a $0,20 \mathrm{~m}$ para os parâmetros densidade do solo e volume total de poros (Tabela 1). Em superfície $(0,00-0,05 \mathrm{~m})$, esse comportamento está diretamente relacionado ao pisoteio animal na área de pastagem (PT) e a mínima mobilização do solo na área de semeadura direta (SD). Em profundidade $(0,15-0,20 \mathrm{~m})$, se deve ao intenso tráfego de máquinas que ocorre no plantio convencional (PC). Resultados semelhantes foram verificados por Bertol et al. (2004), estudando diferentes sistemas de cultivos num Cambissolo Húmico na região do Planalto Sul Catarinense. Os autores observaram que maiores valores de Ds nas áreas de semeadura direta e no plantio convencional quando comparados ao campo nativo, justificando esse padrão ao trânsito de máquinas e de pessoas na área experimental. Resultados similares foram verificados por Albuquerque et al. (2001) no município de Lages-SC e Lanzanova et al. (2007) em Jarí-RS, estudando os efeitos da integração lavoura-pecuária nas propriedades físicas do solo, constataram que a compactação do solo é causada pelo intenso tráfego de máquinas e implementos agrícolas e pelo pisoteio animal, causando aumento da Ds na camada superficial.

$\mathrm{Na}$ área sob semeadura direta, o aumento da densidade na camada superficial está relacionado à consolidação do solo, em razão da baixa intensidade de preparo, apesar da área estar somente há cinco anos sob este sistema de semeadura. 
Tabela 1 - Densidade do solo (Ds), volume total de poros (VTP), macroporosidade (MA), microporosidade (MI), capacidade de campo (CC) e condutividade hidráulica saturada $(\mathrm{K} \theta)$ nas profundidades avaliadas, em um Latossolo Vermelho submetido a diferentes sistemas de manejo e uso.

\begin{tabular}{|c|c|c|c|c|c|c|}
\hline \multirow{3}{*}{$\begin{array}{c}\text { Sistemas de } \\
\text { Manejo }\end{array}$} & Ds & VTP & MA & MI & $\mathrm{CC}$ & $\mathrm{K} \theta$ \\
\hline & $. . \mathrm{kg} \mathrm{dm}^{-3} .$. & \multicolumn{4}{|c|}{ 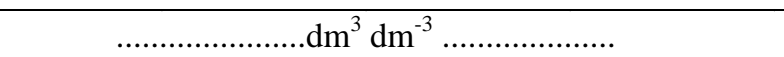 } & $. . \mathrm{mm} \mathrm{h}^{-1} .$. \\
\hline & \multicolumn{6}{|c|}{ Tratamentos } \\
\hline $\mathrm{PC}$ & $1,52 \mathrm{a}$ & $0,43 \mathrm{~b}$ & $0,14 \mathrm{a}$ & $0,33 \mathrm{~b}$ & $0,20 \mathrm{~b}$ & $24,0 \mathrm{a}$ \\
\hline SD & $1,52 \mathrm{a}$ & $0,43 \mathrm{~b}$ & $0,15 \mathrm{a}$ & $0,34 \mathrm{~b}$ & $0,20 \mathrm{~b}$ & 59,0 a \\
\hline PT & $1,50 \mathrm{a}$ & $0,43 \mathrm{~b}$ & $0,15 \mathrm{a}$ & $0,33 \mathrm{~b}$ & $0,18 \mathrm{~b}$ & $23,0 \mathrm{a}$ \\
\hline $\mathrm{CN}$ & $1,38 \mathrm{~b}$ & $0,48 \mathrm{a}$ & $0,16 \mathrm{a}$ & $0,38 \mathrm{a}$ & $0,31 \mathrm{a}$ & 56,0 a \\
\hline $\mathrm{F}^{(1)}$ & $9,76 * *$ & $9,78 * *$ & $0,74^{\mathrm{ns}}$ & $12,15 * *$ & $21,77 * *$ & $5,35^{\mathrm{ns}}$ \\
\hline $\mathrm{CV}(\%)$ & 6,92 & 8,80 & 32,89 & 9,19 & 26,94 & 103,3 \\
\hline \multirow[t]{2}{*}{ dms } & 0,09 & 0,04 & 0,04 & 0,03 & 0,05 & 38,0 \\
\hline & \multicolumn{6}{|c|}{ Profundidades (m) } \\
\hline 0,00 a 0,05 & $1,44 \mathrm{~b}$ & 0,46 a & $0,16 \mathrm{a}$ & $0,33 \mathrm{a}$ & $0,21 \mathrm{a}$ & $40,0 \mathrm{a}$ \\
\hline 0,05 a 0,10 & $1,48 \mathrm{ab}$ & $0,44 \mathrm{ab}$ & $0,15 \mathrm{a}$ & $0,35 \mathrm{a}$ & $0,22 \mathrm{a}$ & $36,0 \mathrm{a}$ \\
\hline 0,10 a 0,15 & $1,48 \mathrm{ab}$ & $0,44 \mathrm{ab}$ & $0,15 \mathrm{a}$ & $0,35 \mathrm{a}$ & $0,23 \mathrm{a}$ & 36,0 a \\
\hline 0,15 a 0,20 & $1,52 \mathrm{a}$ & $0,43 \mathrm{~b}$ & $0,14 \mathrm{a}$ & $0,35 \mathrm{a}$ & $0,22 \mathrm{a}$ & $40,0 \mathrm{a}$ \\
\hline 0,20 a 0,30 & $1,49 \mathrm{ab}$ & $0,44 \mathrm{ab}$ & $0,14 \mathrm{a}$ & $0,35 \mathrm{a}$ & $0,23 \mathrm{a}$ & $48,0 \mathrm{a}$ \\
\hline 0,30 a 0,40 & $1,46 \mathrm{ab}$ & $0,45 \mathrm{ab}$ & $0,16 \mathrm{a}$ & $0,35 \mathrm{a}$ & $0,24 \mathrm{a}$ & $45,0 \mathrm{a}$ \\
\hline $\mathrm{F}^{(1)}$ & $3,85 *$ & $3,66 *$ & $2,53^{\mathrm{ns}}$ & $0,91^{\mathrm{ns}}$ & $1,61^{\mathrm{ns}}$ & $0,51^{\mathrm{ns}}$ \\
\hline $\mathrm{CV}(\%)$ & 3,70 & 4,75 & 14,12 & 10,07 & 16,31 & 64,2 \\
\hline \multirow[t]{2}{*}{$\mathrm{dms}$} & 0,06 & 0,02 & 0,02 & 0,04 & 0,04 & 30,0 \\
\hline & \multicolumn{6}{|c|}{ Tratamentos $\mathrm{x}$ profundidades } \\
\hline $\mathrm{F}^{(1)}$ (Interação) & $1,22^{\mathrm{ns}}$ & $1,21^{\mathrm{ns}}$ & $1,42^{\mathrm{ns}}$ & $3,60^{\mathrm{ns}}$ & $1,03^{\mathrm{ns}}$ & $1,10^{\mathrm{ns}}$ \\
\hline $\mathrm{CV}(\%)$ & 3,96 & 5,00 & 16,16 & 7,07 & 11,34 & 55,0 \\
\hline dms & 0,17 & 0,06 & 0,08 & 0,06 & 0,10 & \\
\hline
\end{tabular}

${ }^{(1)}: * * \mathrm{e}^{*}=$ Significativos $(\mathrm{p}<0,01)$ e $(\mathrm{p}<0,05)$, respectivamente; ${ }^{\text {ns }}=$ Não significativo $(\mathrm{p}<0,05)$. Valores seguidos de letras nas colunas, não diferem entre si, pelo teste de Tukey $(5 \%)$.

Resultados semelhantes foram obtidos por Bertol et al. (2001) num Cambissolo Húmico em Lages-SC e Costa et al. (2003) num Latossolo Bruno em Guarapuava-PR, avaliando as alterações ocorridas nas propriedades físicas causadas pelos sistemas de manejo, observaram que a densidade aumentou em camadas superficiais com a implantação do sistema de semeadura direta. Além disso, no campo nativo, por não ter havido qualquer tipo de manejo de solo ou pastoreio animal há mais de 20 anos, as áreas em razão da vegetação existente apresenta uma grande quantidade de raízes superficiais e profundas, que provavelmente justificam os baixos valores de Ds observados.

Para o volume total de poros (VTP), verifica-se comportamento semelhante ao observado para a Ds, em decorrência do manejo do solo. O aumento dos valores da Ds esteve associado à diminuição do VTP (Tabela 1). A área de campo nativo $(\mathrm{CN})$ foi a que apresentou os maiores valores VTP, diferindo dos outros tipos de manejo. Para a macroporosidade, não foram observadas diferenças significativas entre os tipos de manejo avaliados. Os maiores valores de microporosidade (MI), foram verificados na área de campo nativo, quando comparado aos outros tratamentos (Tabela 1).

Todos os sistemas de manejo (PC, SD, PT e CN) apresentaram valores médios de volumes de macroporos próximos ou superiores daquele considerado ideal, estimado pela relação MA/VTP, de cerca de $1 / 3$ do $\operatorname{VTP}\left(0,33 \mathrm{dm}^{-3} \mathrm{dm}^{-3}\right)$ (Tabela 2), conforme proposto por Taylor \& Aschcroft (1972). Entretanto, alguns valores abaixo de $0,33 \mathrm{dm}^{-3} \mathrm{dm}^{-3}$ na área de PC, provavelmente estão relacionados ao revolvimento do solo na camada superficial $(0,00-0,05 \mathrm{~m})$ e ao pé de grade observado na camada mais profunda $(0,20-0,30 \mathrm{~m})$. Na área 
de SD o menor valor observado ocorre na camada superficial $(0,05-0,10 \mathrm{~m})$, profundidade esta onde é comum ocorrer à compactação do solo, causado pelo trânsito de maquinas pesadas na semeadura.

Bertol et al. (2004) destaca que esse valor (1/3 da VTP) é limitante ao desenvolvimento radicular e que valores menores que estes podem ser restritivos para o crescimento e produtividade das culturas. Menores valores de macroporosidade num Latossolo Vermelho na mesma região foram observados por Torres et al. (2005) que observaram aumento da relação MA/VTP na camada superficial. Esse comportamento foi atribuído pelos autores a ausência do preparo das áreas que estavam em pousio e também pela maior exposição da superfície do solo e consequente destruição dos agregados pelas gotas de chuva na área em plantio convencional.

Com relação à microporosidade, ocorreram diferenças significativas entre os sistemas de manejo (PC, PT e SD) quando comparados ao campo nativo $(\mathrm{CN})$, o que indica que esta variável é mais resistente a alterações quando comparada a macroporosidade, fato este também observado por Bertol et al. (2001, 2004).

Mesmo não ocorrendo diferenças significativas, os altos valores de $\mathrm{K} \theta$ na área sob $\mathrm{SD}$ e $\mathrm{CN}$ sugerem que os espaços deixados pelas raízes das culturas e das coberturas do solo produzem poros contínuos que facilitam o fluxo saturado da água (Tabela 1).

A resistência do solo à penetração é um dos atributos físico mais utilizado como indicativo da compactação do solo (Beautler \& Centurion, 2004). Diante disso, os valores observados com o teste de compactação confirmam que apenas no Campo nativo não ocorreu valores maiores que $2 \mathrm{MPa}$, valor este considerado limitante ao desenvolvimento radicular das culturas, conforme destacado por (Tormena et al., 1998). Nos outros sistemas de manejo (CN, PC, e SD), não ocorreram limitações ao desenvolvimento das culturas até a profundidade de $0,08 \mathrm{~m}$ (Figura 1). Beutler \& Centurion (2004) observaram que a

Tabela 2 - Relação entre macroporos/volume total de poros nos tratamento: plantio convencional (PC), semeadura direta (SD), pastagem (PT) e campo nativo $(\mathrm{CN})$ nas profundidades avaliadas, em um Latossolo Vermelho, em Uberaba-MG.

\begin{tabular}{ccccc}
\hline $\begin{array}{c}\text { Profundidade } \\
(\mathrm{m})\end{array}$ & PC & SD & PT & CN \\
\cline { 2 - 4 } & \multicolumn{2}{c}{ Macroporos/VTP } \\
\hline 0,00 a 0,05 & 0,29 & 0,33 & 0,42 & 0,36 \\
0,05 a 0,10 & 0,38 & 0,29 & 0,33 & 0,34 \\
0,10 a 0,15 & 0,31 & 0,36 & 0,36 & 0,36 \\
0,15 a 0,20 & 0,33 & 0,33 & 0,32 \\
0,20 a 0,30 & 0,34 & 0,37 & 0,33 & 0,34 \\
0,30 a 0,40 & 0,29 & 0,37 & 0,35 & 0,34 \\
Média & 0,35 & 0,34 & 0,35 & 0,34
\end{tabular}

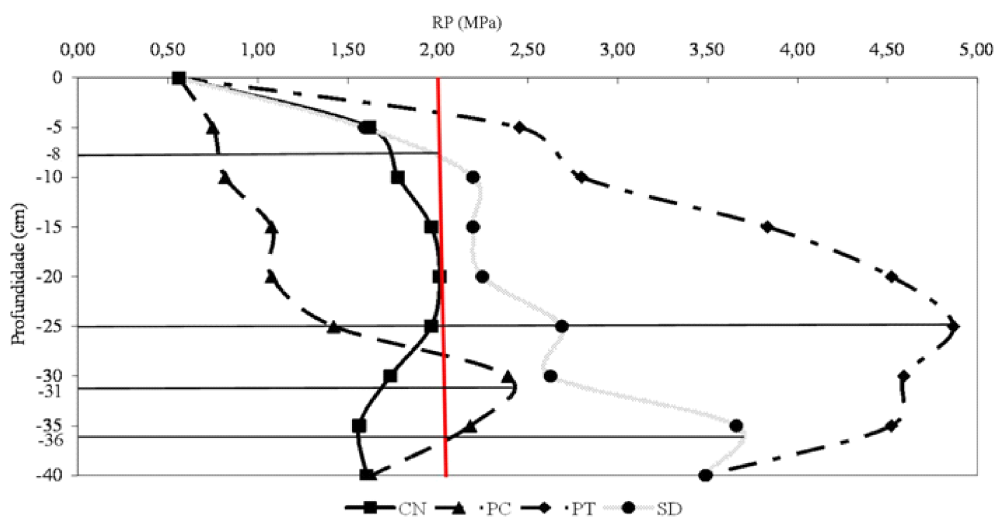

Figura 1 - Resistência do solo à penetração (RP), obtidas em Latossolo Vermelho submetido a diferentes sistemas de manejo e valor limitante para crescimento das culturas de $2 \mathrm{MPa}$ (linha vermelha). CN: Campo nativo; PC: preparo convencional; PT: pastagem; SD: semeadura direta. 
produtividade soja decresce com RP superior a 0,85 MPa. Enquanto que para o milho, em Botucatu-SP, Mahal et al. (2008), não observaram diminuição na produtividade da cultura, quando comparou semeadura direta com preparo do solo com uso de escarificador, onde a RP variando entre 2,73 - 3,14 MPa e 2,31 - 3,11 MPa, respectivamente, 18 meses após a escarificação, até $0,40 \mathrm{~m}$ de profundidade.

Entre os sistemas de manejo avaliados, a área sob pastagem apresentou os maiores valores de RP quando comparados aos outros tratamentos, atingindo o índice máximo de 4,8 MPa aos 0,25 m de profundidade. Resultados semelhantes foram verificados por Ralich et al. (2008), onde a área sob pastagem apresentou os maiores valores de resistência à penetração nas camadas superficiais, o que foi justificado pelo pisoteio dos animais.

Em todos os sistemas de manejo, com exceção do campo nativo, percebe-se uma camada compactada que atinge pico máximo aos 0,25, 0,31 e 0,36 $\mathrm{m}$ de profundidade para PT, PC e SD, respectivamente. Isto talvez possa ser
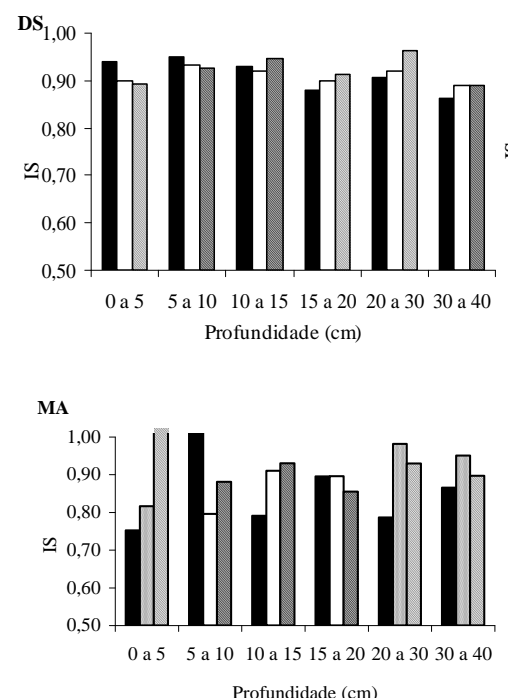

CC

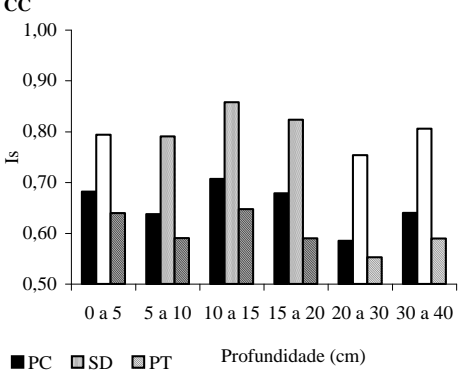

explicada pelo preparo do solo que estas áreas foram submetidas antes da implantação da instalação do experimento, o que provavelmente pode ter promovido a formação de uma camada compactada nestas profundidades. Tormena et al. (1998) avaliaram as modificações ocorridas nas propriedades físicas do solo sob semeadura direta, pelo preparo inicial do solo e tráfego de máquinas. Observaram que os efeitos do tráfego são observados até $0,35 \mathrm{~m}$ e os efeitos do preparo até $0,60 \mathrm{~m}$ de profundidade, que a compactação causada pelas maquinas reduziu a porosidade e aumentou a densidade do solo até $0,20 \mathrm{~m}$ de profundidade. Ralich et al. (2008) destaca que em sistemas de plantio convencional, onde a camada superficial é constantemente revolvida, observa-se o aumento da macroporosidade e diminuição da resistência do solo à penetração.

$\mathrm{O}$ índice de sensibilidade (Is) foi calculado para os atributos Ds, VTP, MA, MI, CC e $\mathrm{K}_{\theta}$ para os sistemas de manejo PC, PT, SD e CN nas diferentes profundidades avaliadas (Figura 2).
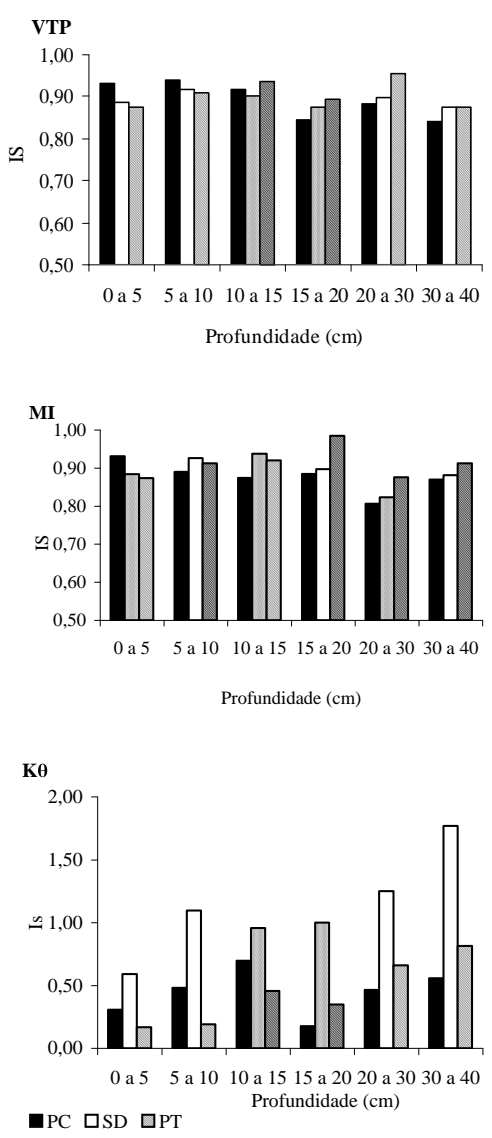

Figura 2 - Índice de sensibilidade (Is) para: Densidade do solo (Ds); Volume total de poros (VTP); macroporosidade (MA); microporosidade (MI); Capacidade de campo (CC) e Condutividade hidráulica saturada (K $\theta$ ) em Latossolo Vermelho submetido a diferentes sistemas de manejo. 
As maiores variações dos Is ocorreram para MA, $\mathrm{CC}$ e $\mathrm{K} \theta$, enquanto que para Ds, VTP e MI os valores ficaram próximos da unidade em todos os tratamentos.

Para o atributo MA, o calculo do Is mostrou maiores variações nas camadas superficiais, pois de $0,00-$ 0,05 m o menor valor ocorreu para PC e o maior para PT, enquanto que de 0,05 - 0,10 m esta situação se inverteu, pois o menor valor ocorreu para PT e o maior para PC, enquanto que para $\mathrm{SD}$, o Is permaneceu constante. Com relação aos atributos $\mathrm{CC}$ e $\mathrm{K} \theta$ para $\mathrm{PC}$ e PT, o Is calculado demonstram o efeito prejudicial desses sistemas de manejo sobre a estrutura do solo, enquanto para SD os valores estiveram mais próximos a unidade $(\mathrm{CN})$. Comportamento similar foi verficado por Costa et al. (2001) e Bertol et al. (2004) observaram efeitos semelhantes avaliando PC e SD.

\section{CONCLUSÕES}

Nas áreas sob preparo convencional, semeadura direta e pastagem nãos foram observadas alterações significativas com relação aos atributos físicos avaliados; 2 Para as profundidades avaliadas só ocorreram diferenças significativas entre as profundidades de $0,0-0,05$ e a de 0,15 a 0,20 $\mathrm{m}$ para os parâmetros densidade do solo e volume total de poros; 3 - Todos os sistemas de manejo (PC, SD, PT e $\mathrm{CN}$ ) apresentaram valores médios de volumes de macroporos próximos ou superiores daquele considerado ideal $\left(0,33 \mathrm{dm}^{-3} \mathrm{dm}^{-3}\right) ; 4$ - No teste de compactação apenas no Campo nativo não ocorreu valores maiores que $2 \mathrm{MPa}$; Nos sistemas de manejo (CN, PC, e SD) não ocorreram limitações ao desenvolvimento das culturas até a profundidade de $0,08 \mathrm{~m}$; 6 - As maiores variações calculadas pelo Is ocorreram para $\mathrm{MA}, \mathrm{CC}$ e $\mathrm{K} \theta ; 7$-. O Is calculado para os atributos $\mathrm{CC}$ e $\mathrm{K} \theta$ nos sistemas PC e PT demonstraram o efeito prejudicial desses sistemas de manejo sobre a estrutura do solo, quando comparados ao SD.

\section{REFERÊNCIAS BIBLIOGRÁFICAS}

ALBUQUERQUE, J.A.; SANGOI, L.; ENDER, M. Efeitos da interação lavoura-pecuária nas propriedades físicas do solo e características da cultura do milho. Revista Brasileira de Ciência do Solo, Viçosa, v.25, p.717-723, 2001.

BERTOL, I.; ALBUQUERQUE, J.A.; LEITE, D.; AMARAL, A.J.; ZOLDAN JUNIOR, W.A. Propriedades físicas do solo sob preparo convencional e semeadura direta em rotação e sucessão de culturas, comparadas às do campo nativo. Revista Brasileira de Ciência do Solo, Viçosa, v.28, n.1, p.155-165, 2004.
BERTOL, I.; BEUTLER, J.F.; LEITE, D.; BATISTELA, O. Propriedades físicas de um Cambissolo Húmico afetadas pelo tipo de manejo do solo. Scientia Agricola,

Piracicaba, v.58, p.555-560, 2001.

BERTOL, I.; SCHICK, J.; MASSARIOL, J.M.; REIS, E.F.; DILLY, L. Propriedades físicas de um Cambissolo húmico álico afetadas pelo manejo do solo. Ciência Rural, Santa Maria, v.30, p.91-95, 2000.

BEUTLER, A.N.; CENTURION, J.F. Compactação do solo no desenvolvimento radicular e na produtividade da soja. Pesquisa Agropecuária Brasileira, Brasília, v.39, n.6, p.581-588, jun. 2004.

BILIBIO, W.D.; CORRÊA, G.F.; BORGES, E.N. Atributos físicos e químicos de um Latossolo, sob diferentes sistemas de cultivo. Ciência e Agrotecnologia, Lavras, v.34, n.4, p.817-822, jul./ago. 2010.

BLAKE, G.R.; HARTGE, K.H. Bulk density. In: KLUTE, A. (Ed.). Methods of soil analysis: physical and mineralogical methods. 2.ed. Madison: Americam Society of Agronomy, 1986. p.363-375.

BOLINDER, M.A.; ANGERS, D.A.; GREEGORICH, E.G.; CARTER, M.R. The response of soil quality indicators to conservation management. Canadian Journal Soil Science, Ottawa, v.79, p.37-45, 1999.

CARPENEDO, V.; MIELNICZUK, J. Estado de agregação e qualidade de agregados de Latossolos Roxos, submetidos a diferentes sistemas de manejo. Revista Brasileira de Ciência do Solo, Campinas, v.14, p.99-105, 1990.

CASTRO FILHO, C.; MUZILLI, O.; PADANOSCHI, A.L. Estabilidade dos agregados e sua relação com o teor de carbono orgânico num Latossolo Roxo distrófico, em função de sistemas de plantio, rotação de culturas e métodos de preparo das amostras. Revista Brasileira de Ciência do Solo, Campinas, v.22, p.527-538, 1998.

COSTA, F.S.; ALBUQUERQUE, J.A.; BAYER, C.; FONTOURA, S.M.V.; WOBETO, C. Propriedades físicas de um Latossolo Bruno afetadas pelos sistemas de plantio direto e preparo convencional. Revista Brasileira de Ciência do Solo, Campinas, v.22, p.527-535, 2003. 
COSTA, A.M.; RIBEIRO, B.T.; SILVA, A.A.; BORGES, E.N. Estabilidade dos agregados de um Latossolo Vermelho tratado com cama de peru. Ciência e Agrotecnologia, Lavras, v.32, n.1, p.73-79, jan./fev. 2008.

CRUZ, L.B.S.; PATERNIANI, J.E.S.; CARVALHO, R.M.B. Caracterização e manejo sustentável do solo Na bacia do Rio Uberaba (MG). Revista Caminhos de Geografia, v.4, n.9, p.31-49, jun. 2003.

\section{EMPRESA BRASILEIRA DE PESQUISA AGROPECUÁRIA. Sistema brasileiro de classificação de solos. Rio de Janeiro, 2006. 412p.}

EMPRESA BRASILEIRA DE PESQUISA

AGROPECUÁRIA. Serviço Nacional de Levantamento e Conservação de Solos. Levantamento de reconhecimento de meia intensidade dos solos e avaliação da aptidão agrícola das terras do Triângulo Mineiro. Rio de Janeiro, 1982. 562p.

FONTANA, A.; BRITO, R.J.; PEREIRA, M.G.; LOSS, A. Índices de agregação e a relação com as substâncias húmicas em Latossolos e Argissolo de tabuleiros costeiros, Campos dos Goytacazes, RJ. Revista Brasileira de Ciências Agrárias, Recife, v.5, n.3, p.291-297, 2010.

KLUTE, A.; DIRKSEN, C. Hydraulic conductivity and diffusivity: laboratory methods. In: KLUTE, A. (Ed.). Methods of soil analysis: part 1. 2.ed. Madison: American Society of Agronomy, 1986. p.687-732.

LANZANOVA, M.E.; NICOLOSO, R.S.; LOVATO, T.; ELTZ, F.L.F.; AMADO, T.J.C.; REINERT, D.J. Atributos físicos do solo em sistema de integração lavourapecuária sob plantio direto. Revista Brasileira de Ciência do Solo, Viçosa, v.31, p.1131-1140, 2007.

LEITE, L.F.C.; FREITAS, R.C.A.; SAGRILO, E.; GALVÃO, S.R.S. Decomposição e liberação de nutrientes de resíduos vegetais depositados sobre Latossolo Amarelo no Cerrado Maranhense. Revista Ciências Agronômicas, Loureno Marques, v.41, n.1, p.29-35, jan./mar. 2010.

LOSS, A.; PEREIRA, M.G.; SCHULTZ, N.; ANJOS, L.H.C.; SILVA, E.M.R. Atributos químicos e físicos de um Argissolo Vermelho-Amarelo em sistema integrado de produção agroecológica. Pesquisa Agropecuária Brasileira, Brasília, v.44, n.1, p.68-75, jan. 2009.
MARCOLAN, A.L.; ANGHINONI, I. Atributos físicos de um Argissolo e rendimento de culturas de acordo com o revolvimento do solo em plantio direto. Revista

Brasileira de Ciência do Solo, Campinas, v.30, p.163170, 2006

PEREIRA, M.G.; LOSS, A.; BEUTLER, S.J.; TORRES, J.L.R. Carbono, matéria orgânica leve e fósforo remanescente em diferentes sistemas de manejo do solo. Pesquisa Agropecuária Brasileira, Brasília, v.45, n.5, p.508-514, maio 2010.

RALICH, R.; MIRANDA, T.M.; OKUMURA, R.S.; BARBOSA, G.M.C.; GUIMARÃES, M.F.; SCOPEL, E.; BALBINO, L.C. Resistência à penetração de um Latossolo Vermelho Amarelo do Cerrado sob diferentes sistemas de manejo. Revista Brasileira de Engenharia Agrícola e Ambiental, Campina Grande, v.12, n.4, p.381-384, 2008.

SILVA, M.A.S.; MAFRA, A.L.; ALBUQUERQUE, J.A.; ROSA, J.D.; BAYER, C.; MIELNICZUK, J. Propriedades físicas e teor de carbono orgânico de um Argissolo Vermelho sob distintos sistemas de uso e manejo.

Revista Brasileira de Ciência do Solo, Campinas, v.30, p.329-337, 2006.

SILVA, R.H.; ROSOLEM, C.A. Crescimento radicular de espécies utilizadas como cobertura decorrente da compactação do solo. Revista Brasileira de Ciência do Solo, Campinas, v.25, p.253-260, 2001.

SILVA, R.R.; SILVA, M.L.N.; FERREIRA, M.M. Atributos físicos indicadores da qualidade do solo sob sistemas de manejo na bacia do Alto do Rio Grande-MG. Ciência e Agrotecnologia, Lavras, v.29, n.4, p.719-730, jul./ago. 2005.

SILVA, W.S.; GUIMARÃES, E.C.; TAVARES, M. Variabilidade temporal da precipitação mensal e anual na estação climatológica de Uberaba, MG. Ciência e Agrotecnologia, Lavras, v.27, n.3, p.665-674, maio/jun. 2003.

STOLF, R. Teoria e teste experimental de fórmulas de transformação dos dados de penetrômetro de impacto em resistência do solo. Revista Brasileira de Ciência do Solo, Campinas, v.15, p.229-235, 1991.

TAYLOR, S.A.; ASHCROFT, G.L. Physical edaphology: the physics of irrigated and nonirrigated soils. San Francisco: W.H. Freeman, 1972. 532p. 
TORMENA, C.A.; ROLOFF, G.; SÁ, J.C.M. Propriedades físicas do solo sob plantio direto influenciadas por calagem, preparo inicial e tráfego. Revista Brasileira de Ciência do Solo, Campinas, v.22, p.301-309, 1998.

TORRES, J.L.R.; PEREIRA, M.G.; ANDRIOLI, I.; POLIDORO, J.C.; FABIAN, A.J. Decomposição e liberação de nitrogênio de resíduos culturais de plantas de cobertura em um solo de cerrado. Revista
Brasileira de Ciência do Solo, Campinas, v.29, p.609$618,2005$.

VALLE JUNIOR, R.F.; PASSOS, A.O.; ABDALA, V.L.; RAMOS, T.R. Determinação das áreas de preservação permanente na bacia hidrográfica do rio Uberaba-MG, utilizando o sistema de informação geográfica (SIG).

Global Science and Technology, v.3, n.1 p.19-29, jan./abr. 2010. 